CLINICAL STUDY

\title{
Early changes in carcinoembryonic antigen but not in calcitonin levels are correlated with the progression-free survival in medullary thyroid carcinoma patients treated with cytotoxic chemotherapy
}

\author{
G Hajje $^{1}$, I Borget ${ }^{2}$, S Leboulleux ${ }^{1}$, C Chougnet $^{1}$, A Al Ghuzlan ${ }^{3}$, H Mirghani $^{4}$, C Caramella $^{5}$, \\ $\mathrm{D} \mathrm{Hartl}^{4}$, M Schlumberger ${ }^{1}$ and E Baudin ${ }^{1}$ \\ Departments of ${ }^{1}$ Nuclear Medicine and Endocrine Tumors, ${ }^{2}$ Biostatistics and Epidemiology, ${ }^{3}$ Pathology, ${ }^{4}$ Head and Neck Surgery and ${ }^{5}$ Radiology, Institut \\ Gustave Roussy, University Paris Sud, 39 Rue Camille Desmoulins, 94805 Villejuif Cedex, France \\ (Correspondence should be addressed to E Baudin; Emails: baudin@igr.fr; G Hajje; hajjgeorges@hotmail.com)
}

\begin{abstract}
Introduction: The prognostic value of serum calcitonin (CT) and carcinoembryonic antigen (CEA) doubling time has been recently demonstrated in medullary thyroid carcinoma (MTC) patients. No study has yet validated the surrogate role of these markers for survival during treatment. The aim of this study was to evaluate, in patients with advanced MTC treated with cytotoxic chemotherapy, the relationship between early changes of serum CT or CEA levels and progression-free survival (PFS). Patients and methods: The files of 28 consecutive metastatic MTC patients with progressive disease, treated with cytotoxic chemotherapy in a single tertiary referral center between 2000 and 2010, were retrospectively reviewed. Serum CT and CEA measurements and radiological Response Evaluation Criteria in Solid Tumors (RECIST) evaluations were collected every 3 months. The relationship between changes in serum CT and CEA levels at 3 months, defined by an increase or a decrease of at least $20 \%$, and PFS according to RECIST 1.0, was estimated using Kaplan-Meier curves and log-rank test.

Results: The median follow-up for the 28 patients was 68 months. According to RECIST, a partial response, a stabilization or a progression was observed in 14, 43, and $43 \%$ of cases respectively. Median PFS from the initiation of cytotoxic chemotherapy was 4.5 months. Median PFS among patients with and without significant CT increase at 3 months was 4.6 and 3.3 months respectively $(P=0.75)$. Median PFS among patients with a significant CEA increase at 3 months was 2.7 months, whereas it was 19.1 months in patients in whom CEA did not increase $(P=0.02)$.

Conclusion: At 3 months, an increase of serum CEA but not of CT levels appears as a valuable surrogate marker of short PFS in MTC patients treated with cytotoxic chemotherapy. A prospective validation is expected.
\end{abstract}

European Journal of Endocrinology 168 113-118

\section{Introduction}

Medullary thyroid carcinoma (MTC) is a rare cancer characterized by the production and secretion of calcitonin (CT) and carcinoembryonic antigen (CEA) into the blood $(1,2,3)$. This activity has promoted numerous studies to investigate the potential role of serum CT or CEA levels as diagnostic or prognostic markers of MTC. CT is not a specific marker for MTC and is secreted in cases of $\mathrm{C}$ cell hyperplasia or neuroendocrine tumors $(1,4,5,6,7)$. Nonetheless, CT is a sensitive marker for MTC and is among the highest sensitive markers in oncology $(1,8,9,10,11,12)$. CEA is a biomarker of several cancers and was found elevated at an advanced stage in MTC (1). After thyroid surgery,
$70 \%$ of sporadic MTC patients are not cured as indicated by persistent elevated CT and CEA levels $(1,13,14,15$, $16,17)$. In these MTC patients, serum CT or CEA doubling times are correlated with overall survival and Response Evaluation Criteria in Solid Tumors (RECIST) progression $(18,19,20)$ and have been proposed as a surrogate marker of overall survival (21).

Nowadays, tyrosine kinase inhibitors (TKIs), especially vandetanib, have been recommended as first-line therapy in the case of aggressive metastatic MTC patients (1) based on phase II and phase III trials in MTC patients that reported higher objective response rates compared with cytotoxic chemotherapy $(22,23)$. Moreover, a recently published pivotal phase III trial using vandetanib demonstrates a significant increase in 
progression-free survival (PFS) in advanced MTC (24). These studies have renewed the interest of clinicians in the search for predictors or surrogates of response in MTC patients treated with TKI in order to better select patients for such therapy as well as for its maintenance. But no strict correlation between early changes in serum CT or CEA levels and tumor response has emerged yet $(22,23,25)$. Only one report describes a correlation of tumor markers and response to treatment in a small series of MTC patients treated with sorafenib (25). Uncoupling impact of TKI on proliferative and secretory pathways of thyroid C cells has been suggested to explain such results (26). In this study, we speculated that cytotoxic chemotherapy could yield to different results due to a different mechanism of tumor cellinduced toxicity.

In order to further investigate the role of $\mathrm{CT}$ or CEA levels as surrogate markers for tumor response in MTC patients, we retrospectively reviewed files of MTC patients who were treated at the Institut GustaveRoussy (IGR) with cytotoxic chemotherapy between January 2000 and December 2010.

\section{Materials and methods}

\section{Patients}

Approval from patients was obtained for this retrospective study. Files of consecutive MTC patients treated at the IGR undergoing cytotoxic chemotherapy for a metastatic MTC between January 2000 and December 2010 were reviewed. Inclusion criteria were: i) confirmed pathological diagnosis of MTC; ii) RECIST 1.0 progressive metastatic disease for more than 1 year at the time of treatment initiation; iii) treatment with systemic cytotoxic chemotherapy; and iv) follow-up every 3 months with serum CT and/or CEA determinations and a morphological evaluation with RECIST 1.0. Exclusion criteria were treatment with TKI drug anytime during the course of the study and changes in the methodology for CT or CEA measurements at the time of chemotherapy initiation.

\section{Serum CT and CEA determinations}

Serum CT level was measured using a MAB immunoradiometric assay (ELSA-CT; CIS Bio International, Gif-surYvette, France; normal value $<10 \mathrm{pg} / \mathrm{ml}$ ). Intra-assay variability was $<7 \%$ and inter-assay variability $<12 \%$.

Serum CEA was measured, before 2005, using a Kryptor technology with intra-assay variability $<3.5 \%$ and inter-assay variability $<5.5 \%$, and after 2005 by a chemiluminescent technique (CEA Access, Beckman Coulter, CA, USA; normal value $<7 \mathrm{ng} / \mathrm{ml}$ ) with interassay variability $<4 \%$.

Serum CT and/or CEA were collected at baseline (at the time of chemotherapy initiation) and at
3 months; a decreasing level was defined as a decrease by more than $20 \%$ of its baseline value, an increasing level was defined as an increase by more than $20 \%$ and a stable level if it ranged between -20 and $+20 \%$ of its basal level.

\section{Imaging and RECIST criteria}

All patients had a morphological evaluation at baseline and every 3 months during chemotherapy consisting of neck, chest, and abdomen computed tomography scan, liver magnetic resonance imaging (MRI), bone scan and spine MRI when considered appropriate. Tumor response was evaluated as RECIST 1.0 every 3 months after initiation of chemotherapy and was compared with baseline results. According to RECIST, results were classified as partial response (PR) if the sum of the target lesion diameters decreased by more than $30 \%$, as progressive disease (PD) if it exceeded $20 \%$ and as stabilization if it was in between (27). In patients with bone metastases only, appearance of a new bone metastasis confirmed by conventional imaging was classified as a progression. In addition, death from any cause was classified as PD. Three patients had bone metastases only, and were followed with bone scan and MRI.

\section{Chemotherapy}

Various protocols were used as first-line chemotherapy. Nine patients received 5-fluorouracil (5FU) with dacarbazine or temozolomide, five patients received 5FU with streptozocin and eight patients received an alternative regimen of 5FU-dacarbazine and 5FU (replaced by doxorubicin in five cases)-streptozocin as described in the literature (28). The remaining six patients were treated by other types of chemotherapy such as gemcitabine, cisplatin combined or not with etoposide, FU, and irinotecan or carboplatin. The median number of cycles was 4.5 (range: $2-12$ ).

\section{Statistical analysis}

Quantitative data were expressed as mean and S.D. and qualitative data were expressed as percentage. PFS was defined as the time between chemotherapy initiation and the first subsequent event (progression or death from any cause). Patients who were alive and who did not progress were censored at the date of their last follow-up visit. PFS was estimated by Kaplan-Meier method. Early changes in serum CT or CEA levels at 3 months and their relationship with PFS were analyzed using the log-rank test. Results were classified as concordant, in case PR, stabilization, or PD on imaging were consistent with serum CT and CEA decreased, stable, or increased levels respectively. Otherwise, results were classified as discordant. Major discordance was defined by CT or CEA decrease or increase in case of 
PD or PR respectively. All reported $P$ values are two sided and the significance level was 0.05. Analyses were performed using SAS Statistical Software version 9.1 (SAS Institute, Inc., Cary, NC, USA).

\section{Results}

\section{Clinical characteristics of patients and initial treatment}

Records of 40 consecutive MTC patients were reviewed (Table 1). Seven patients received a TKI therapy as second- or third-line treatment and five patients did not have a biological or morphological evaluation at 3 months. Overall, 28 patients met the inclusion criteria and formed the basis of this report.

The clinical characteristics of the 28 patients are reported in Table 1 . There were 19 males and nine females, aged between 22 and 75 years with a median age of 58 years. Germinal RET mutation was found in five $(18 \%)$ patients. All patients were initially treated by total thyroidectomy and cervical lymph node dissection. The median time from diagnosis to first distant metastasis was 2 years (range: $0-8$ years) and the

Table 1 Clinical characteristics of patients.

\begin{tabular}{|c|c|}
\hline & $n=28$ patients \\
\hline \multicolumn{2}{|l|}{ Sex } \\
\hline Male & 19 \\
\hline Female & 9 \\
\hline Median age (years; range) & $58(22-75)$ \\
\hline \multicolumn{2}{|l|}{ Stage of tumor at diagnosis } \\
\hline 1 & 0 \\
\hline II & $1(4 \%)$ \\
\hline III & $6(21 \%)$ \\
\hline IV & $17(61 \%)$ \\
\hline Unknown & $4(14 \%)$ \\
\hline $\begin{array}{l}\text { Median time from diagnosis to } \\
\text { first metastasis (years) }\end{array}$ & 2 \\
\hline \multicolumn{2}{|l|}{ Germline RET mutation } \\
\hline Present & $5(18 \%)$ \\
\hline Absent & $14(50 \%)$ \\
\hline Unknown & $9(32 \%)$ \\
\hline $\begin{array}{l}\text { Median time to chemotherapy } \\
\text { since initial diagnosis (years) }\end{array}$ & 2 \\
\hline $\begin{array}{l}\text { Mean/median calcitonin value } \\
\text { (range) before chemotherapy (pg/ml) }\end{array}$ & $\begin{array}{l}32784 / 2221 \\
(33-328000)\end{array}$ \\
\hline $\begin{array}{l}\text { Mean/median CEA value } \\
\text { (range) before chemotherapy (ng/ml) }\end{array}$ & $419 / 83(3-3428)$ \\
\hline \multicolumn{2}{|l|}{ Tumor metastatic organs } \\
\hline Lungs & 14 \\
\hline Liver & 13 \\
\hline Bone & 17 \\
\hline Choroid & 1 \\
\hline Brain & 1 \\
\hline Kidney & 1 \\
\hline \multicolumn{2}{|l|}{ RECIST 1.0: PR or stabilization } \\
\hline 5FU + dacarbazine (nine patients) & 6 \\
\hline $5 \mathrm{FU}+$ streptozocin (five patients) & 4 \\
\hline $\begin{array}{l}\text { 5FU + dacarbazine alternating with } \\
\text { adriamyin + streptozocin (eight patients) }\end{array}$ & 4 \\
\hline Others (six patients) & 2 \\
\hline
\end{tabular}

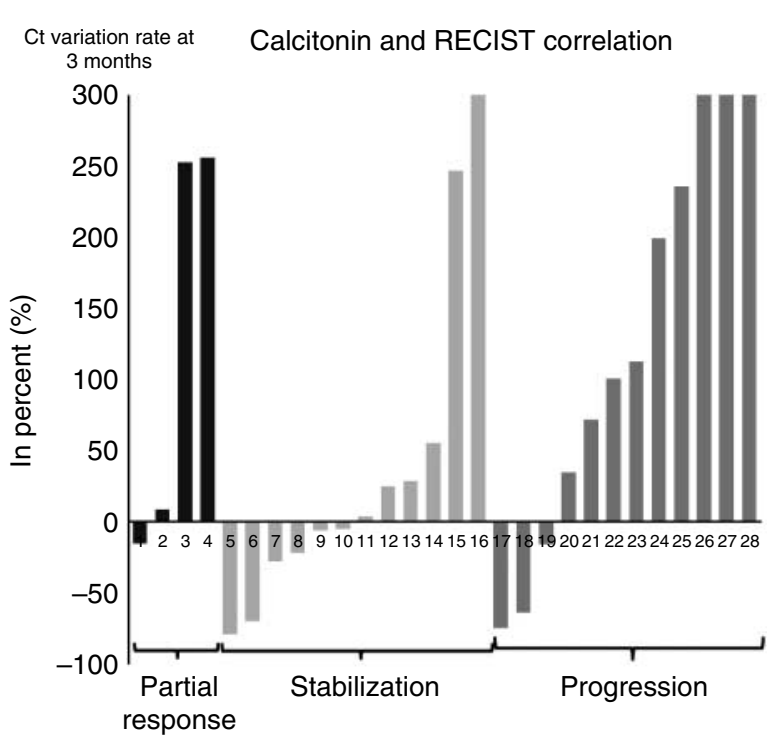

Figure 1 Early changes in calcitonin levels and tumor response (RECIST) at 3 months.

median time from diagnosis to first chemotherapy treatment was also 2 years (range: 0-11 years). Fourteen patients $(50 \%)$ received external radiation therapy to the neck and mediastinum. All patients had metastatic disease with documented progression by imaging over 1 year or less at the time of chemotherapy initiation. The most frequent site of metastases was bones, followed by lungs and liver.

\section{Results of chemotherapy: RECIST 1.0 evaluation and survival}

At 3 months, a PR was observed in four patients (14\%), stabilization in 12 patients (43\%), and PD in 12 patients (43\%). Median PFS and overall survival (OS) were respectively 4.5 months and 2.5 years. Thirteen patients were controlled for more than 6 months: ten of them were treated with 5FU-dacarbazine combined or not with 5FU-streptozocin, and two received 5FUstreptozocin alone. Overall survival at 1 and 5 years were $60 \%(95 \% \mathrm{CI}=42-75)$ and $15 \%(95 \% \mathrm{CI}=5-39)$ respectively.

\section{Early changes in serum CT and CEA levels and tumor response (RECIST) at 3 months}

Early changes in CT levels were evaluable in the 28 patients and concordant with RECIST results in 15 (54\%) cases (Figs 1 and 2). The following discordant variations of CT were observed in 13 patients $(46 \%)$ : increased CT levels in patients with PR (two cases), decreased CT levels in patients with PD (two cases), and increased or decreased CT levels in patients with stable 


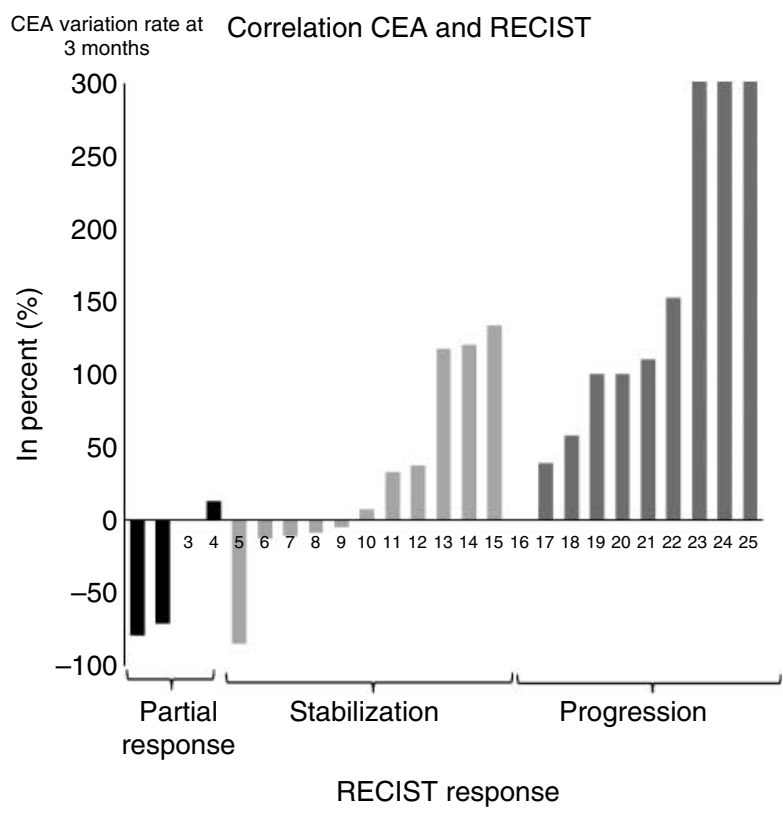

Figure 2 Early changes in CEA levels and tumor response (RECIST) at 3 months.

disease (four and five cases respectively). Major discordance was therefore found in four cases (14\%).

Early changes of serum CEA levels were evaluable in 25 patients and concordant with RECIST results in 19 (76\%) cases. The following discordant changes of CEA were observed in six patients $(24 \%)$ : increased or decreased CEA levels in patients with stable disease (one and five cases respectively). No major discordance was found.

\section{Median PFS as function of early CT or CEA changes}

Median PFS was 4.6 months when CT level was stable or decreasing, and 3.3 months when CT level increased; there was no statistical difference between the two groups $(P=0.75$; Figs 3 and 4$)$.

Median PFS was 19.1 months when CEA level was stable or decreasing, and 2.8 months when CEA level increased; the difference being statistically significant between the two groups $(P=0.02)$.

When a threshold of early CT or CEA change of $50 \%$ was considered, the results were not modified. Furthermore, no correlation between early CT or CEA changes and overall survival was found.

\section{Discussion}

In this study, CEA and CT markers are investigated as surrogates of cell cytotoxicity induced by traditional DNA damage by cytotoxic agents, which modalities of cell cytotoxicity differ from those of the TKIs.
Our study suggests for the first time that in MTC patients treated with cytotoxic chemotherapy, early changes in serum CEA levels at 3 months could be considered as surrogate marker of PFS. Indeed, an increase in CEA level during the first 3 months of chemotherapy was associated with a significantly shorter PFS $(P=0.02)$, and this should lead to discontinuation of cytotoxic chemotherapy. In contrast, the 19.1-month PFS observed in CEA responders validates the use of cytotoxic chemotherapy in these selected patients. No significant relationship was observed between changes in CT levels during the first 3 months of chemotherapy and tumor response or PFS. In the absence of validated predictors of response to cytotoxic chemotherapy in MTC patients, early determination of CEA appears as a useful tool to decide whether to maintain chemotherapy or not. In addition, in the absence of complete remission observed in patients treated by TKI, cytotoxic chemotherapy will probably play a role in the treatment of MTC patients as either post first- or second-line therapy or in future protocols analyzing the impact of drug combinations. In this regard, historical cytotoxic chemotherapies used in neuroendocrine tumors, such as 5FU-dacarbazine, appear the best option.

A surrogate marker can be defined by any biological measurement that is used in therapeutic trials as a substitute for a clinically meaningful endpoint and is expected to predict the effect of the therapy early (29, $30)$. It is used at the initiation of a given treatment to predict tumor response early in a patient to avoid undue toxicity. Recently, CT or CEA doubling time was recommended by ATA guidelines (1) as a marker of progression calculated by using a minimum of four CT values preferably over a 2 -year period. Such recommendations cannot be applied to surrogate markers since the shortest delay of information is required to consider a biomarker as a valuable surrogate. Interestingly, in this study, two measurements at 3 months' interval

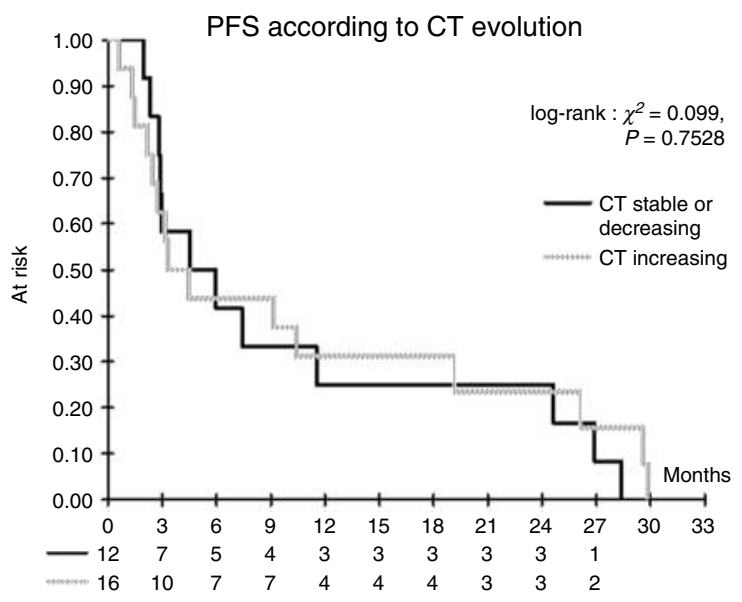

Figure 3 PFS according to changes in calcitonin (CT) levels at 3 months after initiation of cytotoxic chemotherapy. 


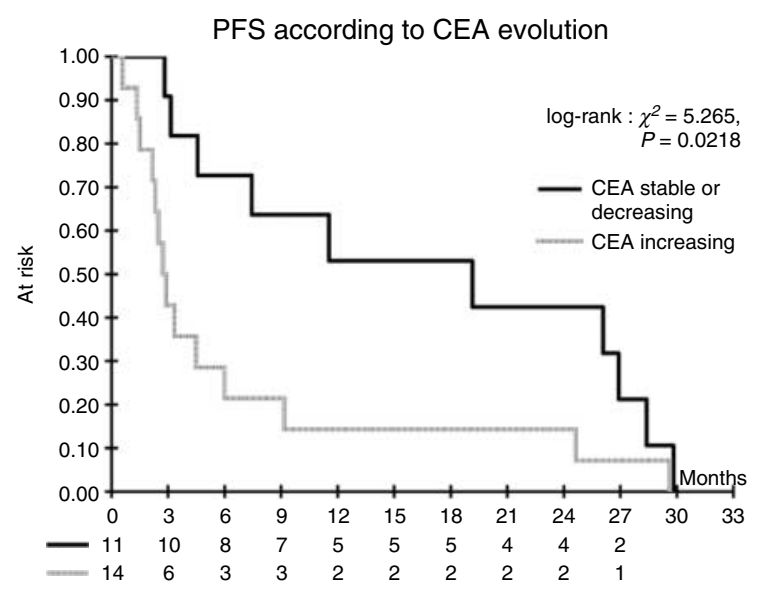

Figure 4 PFS according to changes in CEA levels at 3 months after initiation of cytotoxic chemotherapy.

were found sufficient to predict PFS with CEA measurements. We speculate that treatment intervention in the case of cytotoxic chemotherapy improves the predictability of CEA measurement.

The higher concordance found between CEA and RECIST results compared with CT measurements could not only be related to the high day-to-day variability of CT results but also to a greater influence of drug interference and levels of urea and creatinine $(31,32,33)$, to the rapid degradation of $\mathrm{CT}$ after blood sampling, or to the hook effect in the case of very high levels of CT achieved in metastatic MTC patients $(31,34)$. Surprisingly, no clear correlation has yet been reported between early changes in CT or CEA levels and response to TKI (22, 23, 26). Because RET kinase mediates a physiologic pathway controlling CT secretion, it was expected that RET kinase inhibitors could affect both the secretory activity and the growth of the neoplastic C cells (26). However, no strict correlation was observed (35) and even paradoxical increase in biomarkers was observed in responders $(23,36,37)$. These results suggest that the mechanisms leading to tumor control and marker secretion are dissociated in the setting of TKI administration. In contrast, the present study suggests more straightforward relationship between CEA secretion and tumor control in patients treated with cytotoxic chemotherapy.

\section{Conclusion}

Our study demonstrates that early change in CEA levels at 3 months is a surrogate marker for PFS in advanced MTC treated with cytotoxic chemotherapy. In case of CEA progression at 3 months, discontinuation of cytotoxic chemotherapy should be discussed. A prospective validation is expected to confirm these results.

\section{Declaration of interest}

The authors declare that there is no conflict of interest that could be perceived as prejudicing the impartiality of the research reported.

\section{Funding}

This research did not receive any specific grant from any funding agency in the public, commercial or not-for-profit sector.

\section{Author contribution statement}

G Hajje, I Borget, S Leboulleux, C Chougnet, A Al Ghuzlan, H Mirghani, C Caramella, D Hartl, M Schlumberger, and E Baudin contributed equally to this work.

\section{References}

1 American Thyroid Association Guidelines Task Force, Kloos RT, Eng C, Evans DB, Francis GL, Gagel RF, Gharib H, Moley JF, Pacini F, Ringel MD et al. Medullary thyroid cancer: management guidelines of the American Thyroid Association. Thyroid 200919 565-612. (doi:10.1089/thy.2008.0403)

2 Schlumberger M, Bastholt L, Dralle H, Jarzab B, Pacini F, Smit JWA \& The European Thyroid Association Task Force. ETA guidelines for metastatic medullary thyroid cancer. European Thyroid Journal 20121 5-14. (doi:10.1159/000336977)

3 Brandi ML, Gagel RF, Angeli A, Bilezikian JP, Beck-Peccoz P, Bordi C, Conte-Devolx B, Falchetti A, Gheri RG, Libroia A et al. Guidelines for diagnosis and therapy of MEN type 1 and type 2 . Journal of Clinical Endocrinology and Metabolism $2001865658-5671$. (doi:10.1210/jc.86.12.5658)

4 Guyétant S, Rousselet MC, Durigon M, Chappard D, Franc B, Guerin O \& Saint-André JP. Sex-related C cell hyperplasia in the normal human thyroid: a quantitative autopsy study. Journal of Clinical Endocrinology and Metabolism 199782 42-47. (doi:10.1210/jc.82.1.42)

5 Scheuba C, Kaserer K, Weinhäusl A, Pandev R, Kaider A, Passler C, Prager G, Vierhapper H, Haas OA \& Niederle B. Is medullary thyroid cancer predictable? A prospective study of 86 patients with abnormal pentagastrin tests Surgery $1999 \mathbf{1 2 6}$ 1089-1096. (doi:10.1067/msy.2099.102268)

6 Machens A, Haedecke J, Holzhausen HJ, Thomusch O, Schneyer U \& Dralle H. Differential diagnosis of calcitonin-secreting neuroendocrine carcinoma of the foregut by pentagastrin stimulation. Langenbeck's Archives of Surgery 2000385 398-401. (doi:10.1007/ s004230000169)

7 Baudin E, Bidart JM, Rougier P, Lazar V, Ruffié P, Ropers J, Ducreux M, Troalen F, Sabourin JC, Comoy E et al. Screening for multiple endocrine neoplasia type 1 and hormonal production in apparently sporadic neuroendocrine tumors. Journal of Clinical Endocrinology and Metabolism $1999 \mathbf{8 4} 69-75$. (doi:10.1210/jc. 84.1.69)

8 Machens A, Lorenz K \& Dralle H. Individualization of lymph node dissection in RET (rearranged during transfection) carriers at risk for medullary thyroid cancer: value of pretherapeutic calcitonin levels. Annals of Surgery 2009250 305-310. (doi:10.1097/SLA. Ob013e3181ae333f)

9 Scollo C, Baudin E, Travagli JP, Caillou B, Bellon N, Leboulleux S \& Schlumberger M. Rationale for central and bilateral lymph node dissection in sporadic and hereditary medullary thyroid cancer. Journal of Clinical Endocrinology and Metabolism $2003 \mathbf{8 8}$ 2070-2075. (doi:10.1210/jc.2002-021713)

10 Moley JF. Medullary thyroid carcinoma: management of lymph node metastases. Journal of the National Comprehensive Cancer Network $20108549-556$.

11 Rohmer V, Vidal-Trecan G, Bourdelot A, Niccoli P, Murat A, Wemeau JL, Borson-Chazot F, Schvartz C, Tabarin A, Chabre O et al. 
Prognostic factors of disease-free survival after thyroidectomy in 170 young patients with a RET germline mutation: a multicenter study of the Groupe Francais d'Etude des Tumeurs Endocrines. Journal of Clinical Endocrinology and Metabolism 201196 E509-E518. (doi:10.1210/jc.2010-1234)

12 Cohen R, Campos JM, Salaün C, Heshmati HM, Kraimps JL, Proye C, Sarfati E, Henry JF, Niccoli-Sire P \& Modigliani E. Preoperative calcitonin levels are predictive of tumor size and postoperative calcitonin normalization in medullary thyroid carcinoma. Groupe d'Etudes des Tumeurs à Calcitonine (GETC). Journal of Clinical Endocrinology and Metabolism 200085 919-922. (doi:10.1210/jc.85.2.919)

13 Weber T, Schilling T, Frank-Raue K, Colombo-Benkmann M, Hinz U, Ziegler R \& Klar E. Impact of modified radical neck dissection on biochemical cure in medullary thyroid carcinomas. Surgery 2001130 1044-1049. (doi:10.1067/msy.2001. 118380a)

14 Ukkat J, Gimm O, Brauckhoff M, Bilkenroth U \& Dralle H. Single center experience in primary surgery for medullary thyroid carcinoma. World Journal of Surgery 200428 1271-1274. (doi:10.1007/s00268-004-7608-9)

15 Machens A, Schneyer U, Holzhausen HJ \& Dralle H. Prospects of remission in medullary thyroid carcinoma according to basal calcitonin level. Journal of Clinical Endocrinology and Metabolism 200590 2029-2034. (doi:10.1210/jc.2004-1836)

16 Machens A, Gimm O, Ukkat J, Hinze R, Schneyer U \& Dralle H. Improved prediction of calcitonin normalization in medullary thyroid carcinoma patients by quantitative lymph node analysis. Cancer $2000 \mathbf{8 8}$ 1909-1915. (doi:10.1002/(SICI)1097-0142 (20000415)88:8<1909::AID-CNCR21 > 3.0.CO;2-A)

17 Modigliani E. Type 2 endocrine neoplasms. Clinical aspects. Presse Médicale 199827 628-632.

18 Giraudet AL, Al Ghulzan A, Aupérin A, Leboulleux S, Chehboun A, Troalen F, Dromain C, Lumbroso J, Baudin E \& Schlumberger M. Progression of medullary thyroid carcinoma: assessment with calcitonin and carcinoembryonic antigen doubling times. European Journal of Endocrinology $2008 \mathbf{1 5 8}$ 239-246. (doi:10.1530/EJE-07-0667)

19 Barbet J, Campion L, Kraeber-Bodéré F, Chatal JF \& GTE Study Group. Prognostic impact of serum calcitonin and carcinoembryonic antigen doubling-times in patients with medullary thyroid carcinoma. Journal of Clinical Endocrinology and Metabolism 2005 90 6077-6084. (doi:10.1210/jc.2005-0044)

20 Meijer J, Le Cessie S, Van den hout W, Kievit J, Schoones J, Romijn J \& Smit J. Calcitonin and CEA doubling times as prognostic factors in medullary thyroid carcinoma, a structured meta-analysis. Clinical Endocrinology 201072 534-542. (doi:10.1111/j.13652265.2009.03666.x)

21 Salaun PY, Campion L, Bournaud C, Faivre-Chauvet A, Vuillez JP, Taieb D, Ansquer C, Rousseau C, Borson-Chazot F, Bardet S et al. Phase II trial of anticarcinoembryonic antigen pretargeted radioimmunotherapy in progressive metastatic medullary thyroid carcinoma: biomarker response and survival improvement. Journal of Nuclear Medicine 201253 1185-1192. (doi:10.2967/ jnumed.111.101865)

22 Wells SA Jr, Gosnell JE, Gagel RF, Moley J, Pfister D, Sosa JA, Skinner M, Krebs A, Vasselli J \& Schlumberger M. Vandetanib for the treatment of patients with locally advanced or metastatic hereditary medullary thyroid cancer. Journal of Clinical Oncology 201028 767-772. (doi:10.1200/JCO.2009.23.6604)

23 Schlumberger MJ, Elisei R, Bastholt L, Wirth LJ, Martins RG, Locati LD, Jarzab B, Pacini F, Daumerie C, Droz JP et al. Phase II study of safety and efficacy of motesanib in patients with progressive or symptomatic, advanced or metastatic medullary thyroid cancer. Journal of Clinical Oncology 200927 3794-3801. (doi:10.1200/JCO.2008.18.7815)

24 Wells SA Jr, Robinson BG, Gagel RF, Dralle H, Fagin JA, Santoro M, Baudin E, Elisei R, Jarzab B, Vasselli JR et al. Vandetanib in patients with locally advanced or metastatic medullary thyroid cancer: a randomized, double-blind phase III trial. Journal of Clinical Oncology 201230 134-141. (doi:10.1200/JCO.2011.35.5040)

25 Frank-Raue K, Ganten M, Kreissl MC \& Raue F. Rapid response to sorafenib in metastatic medullary thyroid carcinoma. Experimental and Clinical Endocrinology \& Diabetes 2011119 151-155. (doi:10.1055/s-0030-1262836)

26 Akeno-Stuart N, Croyle M, Knauf JA, Malaguarnera R, Vitagliano D, Santoro M, Stephan C, Grosios K, Wartmann M, Cozens $\mathrm{R}$ et al. The RET kinase inhibitor NVP-AST487 blocks growth and calcitonin gene expression through distinct mechanisms in medullary thyroid cancer cells. Cancer Research 200767 6956-6964. (doi:10.1158/0008-5472.CAN-06-4605)

27 Therasse P, Arbuck SG, Eisenhauer EA, Wanders J, Kaplan RS, Rubinstein L, Verweij J, Van Glabbeke M, van Oosterom AT, Christian MC et al. New guidelines to evaluate the response to treatment in solid tumors (RECIST guidelines). Journal of the National Cancer Institute 200092 205-216. (doi:10.1093/jnci/ 92.3.205)

28 Schlumberger M, Abdelmoumene N, Delisle MJ \& Couette JE. Treatment of advanced medullary thyroid cancer with an alternating combination of 5 FU-streptozocin and 5 FU-dacarbazine. The Groupe d'Etude des Tumeurs à Calcitonine (GETC). British Journal of Cancer 199571 363-365. (doi:10.1038/bjc.1995.73)

29 Katz R. Biomarkers and surrogate markers: an FDA perspective. NeuroRx 20041 189-195. (doi:10.1602/neurorx.1.2.189)

30 Temple R. Are surrogate markers adequate to assess cardiovascular disease drugs? Journal of the American Medical Association 1999282 790-795. (doi:10.1001/jama.282.8.790)

31 Leboeuf R. "Hook effect" in calcitonin immunoradiometric assay in patients with metastatic medullary thyroid carcinoma: case report and review of the literature. Journal of Clinical Endocrinology and Metabolism 200691 361-364. (doi:10.1210/ jc.2005-1429)

32 Morimoto S, Onishi T, Takamoto S, Imanaka S, Fukuo K, Tsuchiya H, Koh E, Yukawa S \& Kumahara Y. Interference in radioimmunoassay of human calcitonin by vitamin $\mathrm{C}$ and urea. Medical Journal of Osaka University 198535 77-82.

33 Toledo SPA, Lourenço DM Jr, Santos MA, Tavares MR, Toledo RA \& Correia-Deur JEM. Hypercalcitoninemia is not pathognomonic of medullary thyroid carcinoma. Clinics 200964 699-706. (doi:10.1590/S1807-59322009000700015)

34 Tommasi M. Hook effect in calcitonin immunoradiometric assay. Clinical Chemistry and Laboratory Medicine 200745 1073-1074. (doi:10.1515/CCLM.2007.328)

35 Kurzrock R, Sherman SI, Ball DW, Forastiere AA, Cohen RB, Mehra R, Pfister DG, Cohen EE, Janisch L, Nauling F et al. Activity of XL184 (cabozantinib), an oral tyrosine kinase inhibitor, in patients with medullary thyroid cancer. Journal of Clinical Oncology 201129 2660-2666. (doi:10.1200/JCO.2010.32.4145)

36 Wells SAJ, Gosnell JE, Gagel RF, Moley J, Pfister D, Sosa JA, Skinner M, Krebs A, Vasselli J \& Schlumberger M. Vandetanib in metastatic hereditary medullary thyroid cancer: follow-up results of an open-label phase II trial. Journal of Clinical Oncology 201028 767-772. (doi:10.1200/JCO.2009.23.6604)

37 Hong DS, Cabanillas ME, Wheler J, Naing A, Tsimberidou AM, Ye L, Waguespack SG, Hernandez M, El Naggar AK, Bidyasar S et al. Inhibition of the Ras/Raf/MEK/ERK and RET kinase pathways with the combination of the multikinase inhibitor sorafenib and the farnesyltransferase inhibitor tipifarnib in medullary and differentiated thyroid malignancies. Journal of Clinical Endocrinology and Metabolism $201196 \quad 997-1005$. (doi:10.1210/jc.2010-1899)

Received 3 September 2012

Revised version received 5 October 2012

Accepted 23 October 2012 